\title{
Associations between high caffeine consumption, driving safety indicators, sleep and health behaviours in truck drivers
}

Filtness, A.J ${ }^{* 1}$, Hickman, $\mathrm{J}^{2}$, Mabry, J.E. ${ }^{2}$, Glenn, $\mathrm{L}^{2}$, Mao, $\mathrm{H}^{2}$, Camden, $\mathrm{M}^{2}$, Hanowski, R.J²

1: Loughborough University, Loughborough, Leicestershire, LE11 3TU, UK

2: Virginia Tech Transportation Institute (VTTI), Center for Truck and Bus Safety, 3500 Transportation Research Plaza, Blacksburg, VA 24061, USA

*Corresponding author:

Ashleigh Filtness:

Loughborough Design School, Loughborough University, Leicestershire, LE11 3TU, UK

Tel: +44 1509226934

Email: A.J.Filtness@lboro.ac.uk

\begin{abstract}
Background: Truck drivers are vulnerable to driver sleepiness due to pressures of shift work and prolonged driving hours; this is a safety concern as sleepiness more than doubles crash risk. Caffeine is a commonly used countermeasure to driver sleepiness. Previous research with truck drivers has demonstrated a positive impact of caffeine consumption on crash risk. However, habitual use of caffeine has the potential to impair night time sleep resulting in increased sleepiness and safety risk. One group that may be particularly vulnerable to the potential negative impacts of high caffeine consumption are those truck drivers who consume $\geq 5$ caffeinated drinks per day $\left(\geq 90^{\text {th }}\right.$ percentile American average daily caffeine consumption).
\end{abstract}

Method: 1,653 self-reported low ( 1 caffeinated drink per day) and 1,354 high ( $\geq 5$ caffeinated drinks per day) caffeine consumers were compared across a range of driving safety indicators, health and sleep variables. All drivers completed an initial background questionnaire including the Epworth Sleepiness Scale (ESS), Berlin Questionnaire (BQ) and Dula Dangerous Driving Index (DDDI). Crashes and driving violations were monitored for up to 3 years (depending on enrolment date). Medical Examination Reports were available for $83.0 \%$ of the 3,007 participants.

Results: High caffeine consumers were more likely to report poor sleep outcomes: shorter average sleep time, (7.08h compared to $7.41 \mathrm{~h}$ ), higher prevalence of excessive daytime sleepiness $(7.5 \%$ compared to $5.7 \%$ ) and higher proportion at high risk of obstructive sleep apnoea (OSA) on the BQ (13.1\% compared with 9.4\%). The higher caffeine consumers were more likely to report negative health behaviours: smoking, alcohol consumption, poor diet and infrequent exercise. Poorer driving safety indicators (negative emotions and aggressive driving on the DDDI) and previous crashes (27.8\% compared to $21.6 \%$ ) were also more common in high than low caffeine consumers.

Conclusion: Caffeine is an effective countermeasure to driver sleepiness, however, high caffeine users do not exhibit any benefit to driving safety indicators. In fact, there is some evidence for safety concern because high caffeine consumers self-report more crashes and worse driving safety indicators than low caffeine consumers. High caffeine use was associated with poor health behaviours. Further research is needed to fully understand the implications of high caffeine use. Interventions aiming to reduce truck driver sleepiness should be cautious in promotion of caffeine in 
isolation; a wholistic approach to improve driver health would likely be more effective than focusing on sleep health alone.

Keywords: truck, driver sleepiness, driver fatigue, caffeine, truck crashes

\section{Highlights}

- Caffeine is an effective countermeasure to driver sleepiness, however, efficacy of habitual high consumption is not established.

- From a sample of 11,414 truck drivers, 1,653 low ( 1 drink per day) and 1,354 high ( $\geq 5$ drinks per day) caffeine consumers were compared.

- High caffeine consumers felt sleepier and reported shorter sleep duration and more irregular sleep patterns.

- High caffeine consumers exhibited poorer health behaviours e.g. tobacco use, greater weekly alcohol consumption, poor diet and fewer exercise sessions.

- Caution is needed in recommending caffeine to manage driver sleepiness as high consumption is associated with poorer health and does not reduce crashes. 


\section{INTRODUCTION}

The trucking industry is vital for transporting the freight goods on which society depends. This is particularly true in the USA where road transport is the major method of freight transport. It is estimated that more than 10 billion tons of freight per year are moved on US roads, equating to approximately $70 \%$ of all freight transportation in the country (American Trucking Association, 2018). To meet this demand truck drivers are exposed to increasing pressures, such as long work hours, reduced sleep periods, expectation to drive at night and over multiple consecutive days, all of which have been associated with increased sleepiness (McCartt et al., 2000). This is concerning as the risk of crashing more than doubles when drivers are sleepy (Bioulac et al., 2017). One countermeasure to increase alertness and combat driver sleepiness is caffeine consumption.

Caffeine is a chemical compound found in many products. Over the last 10 years there has been an increase in caffeine consumed in drinks (Mitchell et al., 2014). This stimulant acts on the brain, but is widely available and subject to minimal regulations. Many everyday drinks (including coffee, tea, energy drinks and sodas) contain caffeine. Consumption of caffeine gives the user a feeling of alertness because caffeine is a neuro inhibitor, that is, it acts on the brain to supress adenosine receptors (Fredholm et al., 1999; Magkos et al., 2005). Adenosine levels are known to increase in the brain with duration since last sleeping. These increasing adenosine levels exert an increase in "sleep pressure" that creates a feeling of sleepiness. By blocking the adenosine receptors feelings of sleepiness will be reduced. However, adenosine continues to accumulate in the brain even though the receptors are blocked (Fredholm et al., 1999). This means that when the caffeine is broken down and removed by the body there is an influx of adenosine joining to the now vacant receptors which can result in extreme increase of sleepiness, sometimes colloquially referred to as a "caffeine crash" (Walker M., 2017).

The positive impact of caffeine in reducing sleepiness and improving task performance are well documented (e.g. Reyner \& Horne, 2000; Metz, 2011; Smith, 2002). Furthermore, the wealth of evidence supporting caffeine use to improve alertness has led to its status as a commonly recommended countermeasure to reduce fatigue. For example, the UK Highway Code states "the most effective ways to counter sleepiness are to drink, for example, two cups of caffeinated coffee and to take a short nap (at least 15 minutes)" (UK Government, 2018). The benefits of caffeine consumption for truck drivers has been reported in several studies. For example, in a case control study of truck crashes, drivers who used caffeine were $63 \%$ less likely to crash than those who did not (Sharwood et al., 2013). Similarly, in a naturalistic study of truck drivers, those who self-reported using caffeine were half as likely to be involved in safety critical events as drivers that did not use caffeine (Camden et al., 2014). Another naturalistic driving study reported a $6 \%$ reduction in safety critical events per 8 ounces of caffeinated beverage consumed (Heaton \& Griffin, 2015). Although there are clear benefits for caffeine use by truck drivers compared to no caffeine at a population level, little is known about the potential for disadvantages of high caffeine consumption.

A high level of caffeine consumption has the potential for negative health consequences, with one key problem being the impact on sleep. Caffeine has a half-life of 3 to 7 hours (Kaplan et al., 1997), meaning that 7 hours after consumption half the amount of caffeine could still be present in the body. Consequently, people who consume high amounts of caffeine during the day will likely still have the caffeine in their system at night time which may impair their sleep. This may affect both the quantity and quality of sleep (Carrier et al., 2009). Within controlled laboratory experiments caffeine has consistently been shown to increase sleep latency, shorten sleep duration and reduce the amount of deep sleep obtained (for review see Roehrs \& Roth, 2008). 
A further problem associated with caffeine is its addictive nature. Caffeine dependency develops at relatively low daily levels (Roehrs \& Roth, 2008) and it is difficult to determine the impact that habitual high caffeine consumption might have on the use of additional caffeine as an acute countermeasure to driver sleepiness. The more caffeine a person consumes, the more accustomed to it a person becomes, and they may need to consume greater volumes of caffeine to maintain the same baseline alertness level. Despite the potential concern, no studies were identified that specifically considered the influence of habitual caffeine consumption on the use of acute caffeine as a countermeasure to driver sleepiness. However, it has been reported that in regularly administering caffeine to both habitual and non-habitual consumers there was no difference in the acute benefits of caffeine on attention, reaction time and working memory between the groups (Haskell et al., 2005). Also, the impact of acute caffeine on athletic performance is not influenced by habitual caffeine consumption (Gonçalves et al 2017). This suggests that caffeine can continue to improve alertness even with habitual consumption. Beyond this, evidence is limited as protocols to investigate the impact of caffeine commonly require participants who are usually caffeine consumers to abstain from caffeine for a number of days before the study. As such, there is some discussion over whether the findings of such laboratory studies are confounded by the reversal of caffeine withdrawal, rather than benefit of the caffeine per se (Heatherley, 2011).

Although there is evidence that caffeine use reduces crash risk, it is naïve to recommend caffeine as the only answer to crash safety without considering the broader implications for driver's health. High levels of caffeine consumption place pressure on the body, the long-term impacts of which are complex. For example, in a controlled laboratory study, high caffeine consumption was shown to increase the blood pressure of infrequent caffeine consumers (Corti et al., 2002). Although it is not known if similar effects would be found with high caffeine consumers, any potential influence of caffeine consumption on driver health is concerning because poor health and chronic conditions such as cardiovascular disease and obstructive sleep apnoea (OSA) are associated with increased crash risk (Apostolopoulos et al., 2013; Burks et al., 2016; Howard et al., 2004; Thiese et al., 2015), and the prevalence of these conditions is often high amongst truck drivers, likely due to their associations with obesity and the higher obesity rates among drivers. Furthermore, caffeine has been shown to influence behaviour. For example, there is some evidence that habitual caffeine consumers are more impulsive (Giles et al., 2017) and that high caffeine consumption in young adults is associated with sensation seeking behaviour (Jones \& Lejuez, 2005). If these behaviours are translated to driving then high caffeine consumers may be more likely to exhibit risk taking behaviour which is associated with an increased crash risk (Jonah, 1997).

The current study focuses on high ( $\geq 5$ drinks per day) caffeine consumers, that is, those who daily consume more caffeine than $90 \%$ of the US population (Mitchell et al., 2014). By focusing on this group, the current study seeks to identify whether high caffeine consumption is of concern for truck drivers in relation to driving safety indicators and health behaviours. High caffeine consumers will be compared to low ( 1 drink per day) caffeine consumers. Low caffeine consumers are defined as those that consume less than the mean ( 2 drinks per day) daily caffeine intake of the US population (Mitchell et al., 2014). Nil caffeine users are not considered in this study because they are unusual compared to the majority of the US population who do consume caffeine (92\%) (Mitchell et al., 2014). By limiting the study to caffeine consumers the results will be focused on the influence of caffeine itself, rather than on a comparison with nil users, which has the potential to identify trait differences between those who consume caffeine and those who choose to abstain from caffeine (Roehrs \& Roth, 2008). 


\section{METHOD}

\section{Participants}

Data were collected from a convenience sample of 11,414 truck drivers participating in the Commercial Driver Safety Risk Factors (CDSRF) study (Mabry, J.E. 2019). Drivers were recruited at eight locations across the USA: Illinois, Ohio, Kentucky, New Jersey, Virginia, Georgia, Texas and California. Seven of the recruitment sites were associated with the same carrier, and the eighth site was an independent occupational health clinic located in Virginia. All drivers completed an initial background questionnaire upon enrolment in the study, and drivers' subsequent crashes and driving violations were monitored for up to three years (depending on enrolment date). Drivers were recruited during driver orientation and offered $\$ 20$ for completing the background questionnaire. Overall, the response rate to the background questionnaire was $62 \%$. The data presented in this paper are a subset of 3,007 participants from the original study (see section 2.3.1 for inclusion/exclusion criteria).

The study received ethical approval from Virginia Tech Institutional Review Board, approval number 10-704.

\section{Measures}

Three sources of information were used to collect data: 1 . Background questionnaire - a self-report paper-based survey completed during enrolment in the study; 2 . Medical examination report - a certification required for holding a commercial driver license completed by a certified medical examiner; 3. Database records of any crashes or driving-related violations occurring in the three years after study enrolment. Data records were linked between sources using the driver's unique commercial driver license (CDL) number. Once all data were collected and matched by CDL number, all personally identifying information (including the CDL number) were removed and an anonymised ID was created for each driver.

\section{Background questionnaire}

Participants who elected to complete the questionnaire did so during the driver orientation at the participating carrier and returned it to a trained carrier employee at the terminal who mailed them to VTTI. Drivers also had the option of taking the survey home and return via mail to the research team. The survey took approximately 30 minutes to complete and was available in English or Spanish. The 15 page questionnaire had four major components: i) Demographic data e.g. age, height and weight; ii) Self-report health assessment e.g. alcohol consumption, exercise and sleep habits, diet rating and the number of caffeinated drinks consumed per day; iii) driving-related questions e.g. how long participants had been driving a commercial vehicle, prior involvement in crashes and moving violations in the previous three years, and iv) a selection of standardised survey tools including the Epworth Sleepiness Scale (ESS), the Berlin Questionnaire (BQ), and the Dula Dangerous Driving index (DDDI). Two additional survey tools, the Survey of Recent Life Experiences and the Social Desirability Scale, were completed but are not considered in the current work.

\section{Epworth Sleepiness Scale (ESS)}

The ESS requires participants to rate their chance of dozing from 0 (no chance) to 3 (high chance) in 12 different situations. Scores are totalled, with participants scoring 12 or more considered to have excessive daytime sleepiness (Johns, 1991).

\section{Berlin Questionnaire (BQ)}

The Berlin Questionnaire is a self-report screening tool for obstructive sleep apnoea (OSA) (Netzer et al., 1999). OSA is a sleep disorder resulting in the repeated collapse of the airway during sleep. At each airway collapse the sufferer's sleep is disturbed, happening multiple times per hour 
(Hardinge 2008). Untreated OSA is a safety concern because commercial vehicle drivers with untreated OSA are at increased risk of vehicle crashes (Tregear et al 2009). The BQ screening tool includes ten questions across three categories: snoring, fatigue and blood pressure. Answers to category 3 also consider the respondent's body mass index (BMI). Each category is independently scored and calculated as being positive or negative. Respondents demonstrating a positive outcome in two or more categories are considered at overall high risk for OSA.

\section{Dula Dangerous Driving index (DDDI)}

The DDDI assesses likelihood of driving dangerously by rating how often drivers engage in 31 different driving behaviours/situations from 1 (never) to 5 (always) (Dula et al, 2003). The questions cover three subscales: negative emotion while driving (nine questions relating to irritability and tendency to become annoyed with other drivers), aggressive driving (seven questions relating to engaging in behaviours intentionally meant to annoy, irritate or punish other drivers) and risky driving (12 questions related to willingness to engage in unsafe driving behaviours). The questions relating to the three areas are interspersed throughout the questionnaire. Scores for each of the three traits are totalled independently. The higher the score, the greater the propensity for each driving trait.

\section{Medical Examiner Report for Commercial Driver Fitness Determination}

It is a requirement for holding a Class A CDL in the USA to have passed a medical examination report. This information is collected using the standard Federal Motor Carrier Safety Administration (FMCSA) form (FMCSA, n.d.). The examination includes biographical information e.g. height and weight followed by 64 items related to health. The health sections of the form include practical tests e.g. for hearing and vision, self-report health history questions and a physical examination conducted by a certified medical examiner. Finally, there are three sections for open comments from the driver and medical examiner. All open-ended comments on the form were manually transcribed and coded.

Possible outcomes of the Medical Examination Report are: Qualified (fit to drive for the next two years), Periodic (fit to drive, but to be reviewed sooner than two years), temporarily disqualified (deemed medically unfit to drive currently), failed (deemed medically unfit to drive).

At the time the study commenced all drivers hired (or rehired) by the participating carrier were required to undergo a medical examination during the orientation program. Early into the study, this requirement was revoked and newly hired drivers who had a certified Medical Examination Report completed within the previous six months were no longer required to undergo a new Medical Examination Report. Medical Examination Reports completed prior to study enrolment were not made available for analysis in the current work, consequently, Medical Examination Reports were available for $83.0 \%$ of the 3,007 participants.

\section{Safety indicators}

Four self-reported safety indicators and three objective prospective safety indicators were considered. The self-report measures were taken from the background questionnaire and included the answer to the question "Over the past three years, have you had any crash in any vehicle, either personal or commercial?" and the outcome of each of the three DDDI subscales.

The objective data were collected up to three years after the driver enrolled in the study from three sources. First, the participating carrier kept a record of all crashes for each driver during their employment with the participating carrier. This database included crashes of all severity which occurred on road. Crashes occurring off-road e.g. car parks or delivery locations were excluded unless involving another moving vehicle. Records were for the duration of employment with that carrier or until the cessation of data collection (which was up to three years). Second, the Motor 
Carrier Management Information System (MCMIS) documents crashes which have been reported to the Department of Transport (DOT). All crashes which result in a fatality, injury requiring immediate medical attention, or one or more vehicles being towed away from the scene are DOT reportable. MCMIS was used to track crashes for drivers who had left the carrier. With such high turnover in the industry, it was critical to continue tracking drivers if they left their original carrier. Third, records of driving-related moving violations were collected from the Commercial Driver's License Information System (CDLIS). Violations associated with crashes already in the MCMIS data were removed as had the crash not occurred it is likely the moving violation conviction would not have been recorded. Records of all participating drivers were monitored in MCMIS and CDLIS for up to three years after study enrolment, regardless of length of employment at the participating carrier. Each participant was coded as having $\geq 1$ record or 0 records in each of the three databases.

\section{Data analysis}

\section{Inclusion/exclusion criteria}

Inclusion was based on the answer to the background questionnaire question: "How many cups/glasses/pills of coffee or other caffeinated beverages or energy supplements do you have per day?" Two groups of participants were created: "high" caffeine consumers reported consuming five or more caffeinated servings per day, and the "low" caffeine consumers reported consuming one caffeinated serving per day. The definition of high caffeine consumption was $\geq 5$ servings to be indicative of consumption at the $90^{\text {th }}$ percentile of the US population, as determined by a recent survey of 37,602 Americans about caffeine intake where intake from the $90^{\text {th }}$ percentile consumer was reported as $380 \mathrm{mg} /$ day (approximately 5 cups of coffee based on $75 \mathrm{mg} /$ coffee) (Mitchell et al., 2014). In the case of canned/bottled drinks, the current study defined one drink as $8 \mathrm{oz}$ (approximately $237 \mathrm{ml}$ ). A group of low caffeine consumers was chosen as the comparison group. Low was defined as one caffeinated drink per day, this being less than the mean consumption (165 $\mathrm{mg} /$ day; approximately two cups of coffee based on of $75 \mathrm{mg} /$ coffee) reported by Mitchell et al. (2014). Nil caffeine consumers were excluded as they are an unusual self-selected group compared to most (92\%) of the US population of similar age who do consume caffeine (Mitchel et al., 2014). Further, comparison to a nil caffeine consumption group was avoided as this might inadvertently identify genetic or trait differences between the types of people who chooses to consume caffeine compared to those who choose not to, rather than investigating the impact of caffeine itself (Roehrs \& Roth, 2008). Moderate ( $2-4$ drinks per day) caffeine consumers were excluded to ensure a distinct difference between the groups. The focus was specifically on unusually high caffeine consumers, so it was desirable to have a distinct group of extreme difference with which to compare. Since this is one of the first studies to consider high caffeine consumption in truck drivers any differences between these extreme groups are of value to inform future research. In addition, because caffeine consumption was self-reported, the data were not considered sufficiently controlled to employ the absolute amount of caffeine a driver reported consuming as a predictor variable. By grouping together all those drivers that reported $\geq 5$ drinks per day the data is considered sufficiently robust to state that these are truly representative of high caffeine consumers.

Participants were excluded from analysis if data for the question about caffeine was missing, or if they answered the question by either: listing a type of drink e.g. coffee with no indication of volume (546 out of 11,414: 4.8\%), reporting consuming 0 (3,525 out of 11,414: 30.9\%), or between 2 and 4 drinks per day (4,336 out of 11,414: 38.0\%). Twelve participants who described high caffeine use in words e.g. "coffee all day", or "excessive amounts" were included in the high group. 
The final dataset included 3,007 participants: 1,653 low caffeine consumers and 1,354 high caffeine consumers. Of the 10,868 participants who provided usable information about volume of caffeine consumed, $15.2 \%$ met the low caffeine use criteria and $12.5 \%$ met the high caffeine use criteria.

Statistical analysis

A statistical analysis was completed using IBM SPSS 23 statistical software (IBM Corp., Armonk, NY, USA). An alpha level of 0.05 was used to determine statistical significance $\left({ }^{*}\right)$. Comparisons were made between the high and low caffeine consumer groups categorical data using Chi-square $(\chi 2)$ tests with Cramer's V $(\phi c)$ as an estimate of effect size. The remaining variables were analysed using independent $t$ test (normally distributed data) with Cohens $d$ as an estimate of effect size and MannWhitney U-tests (skewed data) with $\mathrm{Eta}^{2}$ as an estimate of effect size.

Binary logistic regression was performed to identify the variables most relevant for predicting an individual would be in the high caffeine consumer group. In line with the focus of the paper binary logistic regression was selected to create a model which directly compared between high and low caffeine consumers. Only variables for which at least $90 \%$ of participants had usable data were considered. In the interests of parsimony, only those variables which statistically significantly varied between the high and low group were included in the model. All variables including background variables were considered eligible to be entered in the model and were not used as control variables.

\section{RESULTS}

In total, 1,653 drivers met the inclusion criteria for the low caffeine consumers group and 1,354 drivers for the high caffeine consumers group. Medical Examiner Reports were available for 1,358 (82.2\%) of the low caffeine consumers and $1,137(84.0 \%)$ of the high caffeine consumers. Participant demographics are presented in Table 1. In total 1,432 (86.7\%) of the low caffeine group and 1,183 $(87.4 \%)$ of the high caffeine group provided their age. The majority $(83.7 \%)$ of the high caffeine group consumed between 5 and 10 caffeinated drinks per day.

\begin{tabular}{llll}
\hline & $\begin{array}{l}\text { Low caffeine } \\
\text { consumers } \\
\text { Mean (SD) range }\end{array}$ & $\begin{array}{l}\text { High caffeine } \\
\text { consumers } \\
\text { Mean (SD) range }\end{array}$ \\
\hline $\begin{array}{l}\text { Caffeinated drinks } \\
\text { per day }\end{array}$ & $M=1$ & $\begin{array}{l}M=7.51(3.8), \text { range }= \\
5-42,\end{array}$ \\
Months held CDL & $M=87.56(104.1)$, & $M=113.24(118.2)$, & $t(3,005)=6.330, p<$ \\
& range $=0-1180$ & range $=0-582$ & $.001, d=0.23^{*}$ \\
Age (years) & $M=41.2(10.7)$, & $M=42.1(11.2)$, range & $t(2613)=2.104, p=$ \\
& range $=21-71$ & $=21-70$ & $.035, d=0.08^{*}$ \\
\hline
\end{tabular}

Table 1 Participant demographics for high and low caffeine consumers. ${ }^{*}$ denotes significant difference $(p<0.05)$

\section{Safety indicators}

All participants had data available for all driving safety indicators. For all self-report measures the high caffeine consumers were significantly riskier than the low caffeine consumers. In particular, having a crash in the previous three years demonstrated the largest effect size. No significant differences were reported between the groups within the carrier crash, MCMIS or CDLIS databases. Safety indicators are report in Table 2.

$\begin{array}{ll}\text { Low caffeine } & \text { High } \\ \text { consumers } & \text { caffeine } \\ & \text { consumers }\end{array}$




\begin{tabular}{|c|c|c|c|}
\hline & $\begin{array}{l}\text { Percentage or } \\
\text { Mean (SD) range }\end{array}$ & $\begin{array}{l}\text { Percentage } \\
\text { or Mean } \\
\text { (SD) range }\end{array}$ & \\
\hline $\begin{array}{l}\text { Self-report crash in } \\
\text { previous } 3 \text { years }\end{array}$ & $21.6 \%$ & $27.8 \%$ & $\chi^{2}(1)=15.739, p<.001, \phi_{c}=.072^{*}$ \\
\hline $\begin{array}{l}\text { DDDI Negative } \\
\text { emotions (out of 45) }\end{array}$ & $\begin{array}{l}16.4(5.4) \text { range }= \\
0-40\end{array}$ & $\begin{array}{l}19.1(5.5) \\
\text { range }=0- \\
41\end{array}$ & $t(3005)=13.481, p<.001, d=0.49 *$ \\
\hline $\begin{array}{l}\text { DDDI aggressive } \\
\text { driving (out of 35) }\end{array}$ & $\begin{array}{l}8.6(2.5) \text { range }=0- \\
25\end{array}$ & $\begin{array}{l}9.7(3.3) \\
\text { range =0- } \\
28\end{array}$ & $t(3005)=10.789, p<.001, d=0.40^{*}$ \\
\hline $\begin{array}{l}\text { DDDI risky driving (out } \\
\text { of } 60 \text { ) }\end{array}$ & $\begin{array}{l}14.5(3.6) \text { range }= \\
0-52\end{array}$ & $\begin{array}{l}15.0(3.8) \\
\text { range }=0- \\
45\end{array}$ & $t(3005)=3.723, p<.001, d=0.14^{*}$ \\
\hline Carrier reported crash & $10.6 \%$ & $12.5 \%$ & $\chi^{2}(1)=2.637, p=.104, \phi_{c}=.030$ \\
\hline MCMIS crash & $2.8 \%$ & $3.3 \%$ & $\chi^{2}(1)=.5798, p=.447, \phi_{c}=.014$ \\
\hline CDLIS violation & $6.4 \%$ & $6.1 \%$ & $\chi^{2}(1)=.101, p=.751, \phi_{c}=.006$ \\
\hline
\end{tabular}

Table 2 Self-report and objective risky driving measures for high and low caffeine consumers.

* denotes significant difference $(p<0.05)$

\section{Health}

Table 3 reports the health measures from the background questionnaire. Overall the high caffeine consumers show greater propensity for sleep/fatigue-related difficulties, including: a higher ESS, greater prevalence of excessive daytime sleepiness (EDS), higher risk of OSA, irregular sleep schedules and shorter average sleep duration.

In terms of general health, drivers in the high caffeine group reported poorer health behaviours including higher tobacco use, greater alcohol consumption, poorer rating of diet and fewer exercise sessions per week. Despite the difference in health behaviour there was no significant difference in BMI.

\begin{tabular}{|c|c|c|c|}
\hline $\begin{array}{l}\text { Variable } \\
\text { ( } \mathrm{n} \text { low caffeine: } \mathrm{n} \text { high } \\
\text { caffeine) }\end{array}$ & $\begin{array}{l}\text { Low caffeine } \\
\text { consumers } \\
\text { Percentage or } \\
\text { Mean (SD) range }\end{array}$ & $\begin{array}{l}\text { High } \\
\text { caffeine } \\
\text { consumers } \\
\text { Percentage } \\
\text { or Mean } \\
\text { (SD) range } \\
\end{array}$ & \\
\hline \multicolumn{4}{|l|}{ Sleep/fatigue related } \\
\hline $\begin{array}{l}\text { ESS score } \\
(1653: 1354)\end{array}$ & $\begin{array}{l}4.92(3.7) \text { range }= \\
0-23\end{array}$ & $\begin{array}{l}5.77(5.1) \\
\text { range }=0- \\
21\end{array}$ & $t(3005)=6.357, p<.001, d=0.49 *$ \\
\hline $\begin{array}{l}\text { EDS }(E S S \geq 12) \\
(1653: 1354)\end{array}$ & $5.7 \%$ & $7.5 \%$ & $\chi^{2}(1)=4.165, p=.041, \phi_{c}=.037^{*}$ \\
\hline $\begin{array}{l}\text { High risk of OSA (BQ) } \\
(1653: 1354)\end{array}$ & $9.4 \%$ & $13.1 \%$ & $\chi^{2}(1)=10.312, p=.0 .01, \phi_{c}=.059^{*}$ \\
\hline $\begin{array}{l}\text { Average hours sleep in } \\
24 \mathrm{~h} \\
(1601: 1291)\end{array}$ & $\begin{array}{l}7.41(1.5) \text { range }= \\
0-18\end{array}$ & $\begin{array}{l}7.08(1.5) \\
\text { range }=0- \\
15\end{array}$ & $U=880831.5, p<.001, E t a^{2}=0.02 *$ \\
\hline $\begin{array}{l}\text { Regular sleep } \\
\text { schedule } \\
(1653: 1354)\end{array}$ & $\begin{array}{l}\text { No: } 14.8 \% \\
\text { Yes: } 53.1 \% \\
\text { Sometimes: } 32.1 \%\end{array}$ & $\begin{array}{l}\text { No: } 21.9 \% \\
\text { Yes: } 41.6 \% \\
\text { Sometimes: } \\
36.5 \%\end{array}$ & $\chi^{2}(2)=46.111, p<.001, \phi_{c}=.124^{*}$ \\
\hline
\end{tabular}




\begin{tabular}{|c|c|c|c|}
\hline \multicolumn{4}{|l|}{ General health } \\
\hline $\begin{array}{l}\text { BMI } \\
(1250: 998)\end{array}$ & $\begin{array}{l}32.00(7.2) \text { range }= \\
16.89-65.26\end{array}$ & $\begin{array}{l}32.29(7.4) \\
\text { range = } \\
17.09- \\
68.84\end{array}$ & $t(2246)=.932, p=.352, d=0.04$ \\
\hline $\begin{array}{l}\text { BMI category } \\
(1250: 998)\end{array}$ & $\begin{array}{l}<18.5: 0.2 \% \\
\geq 18.5-25: 14.1 \% \\
\geq 25-30: 30.2 \% \\
\geq 30-35: 27.4 \% \\
\geq 35-40: 15.3 \% \\
\geq 40: 12.8 \%\end{array}$ & $\begin{array}{l}<18.5: 0.9 \% \\
\geq 18.5-25: \\
13.8 \% \\
\geq 25-30: \\
27.9 \% \\
\geq 30-35: \\
26.5 \% \\
\geq 35-40: \\
17.1 \% \\
\geq 40: 13.8 \%\end{array}$ & $\chi^{2}(5)=7.456, p=.189, \phi_{c}=.058$ \\
\hline $\begin{array}{l}\text { Use tobacco products } \\
(1653: 1354)\end{array}$ & $29.8 \%$ & $62.5 \%$ & $\chi^{2}(1)=322.606, p<.001, \phi_{c}=.179 *$ \\
\hline $\begin{array}{l}\text { Does exercise } \\
(1653: 1354)\end{array}$ & $61.4 \%$ & $55.5 \%$ & $\chi^{2}(1)=95.856, p<.001, \phi_{c}=.328^{*}$ \\
\hline $\begin{array}{l}\text { Moderate exercise } \\
\text { sessions per week } \\
(1653: 1354)\end{array}$ & $\begin{array}{l}2.39(2.0) \text { range }=0 \\
-8\end{array}$ & $\begin{array}{l}1.91(2.2) \\
\text { range }=0- \\
8\end{array}$ & $U=939975.0, p<.001, E t a^{2}=0.02 *$ \\
\hline $\begin{array}{l}\text { Alcoholic drinks per } \\
\text { week } \\
(511: 433)\end{array}$ & $\begin{array}{l}2.94(2.5) \text { range }=0 \\
-20\end{array}$ & $\begin{array}{l}4.41(5.1) \\
\text { range }=0- \\
42\end{array}$ & $U=90036.0, p<.001, E t a^{2}=0.03^{*}$ \\
\hline $\begin{array}{l}\text { Days of the week on } \\
\text { which alcohol is drunk } \\
\text { (524:427) }\end{array}$ & $\begin{array}{l}1.37(0.8) \text { range }=0 \\
-7\end{array}$ & $\begin{array}{l}1.53(1.1) \\
\text { range = } 1- \\
7\end{array}$ & $U=105239.0, p=.049, E_{t a}^{2}=0.01 *$ \\
\hline $\begin{array}{l}\text { Self-rating of diet } \\
\text { (from poor }=1 \text { to } \\
\text { excellent }=5) \\
(1633: 1334)\end{array}$ & $\begin{array}{l}2.94(0.8) \text { range }=1 \\
-5\end{array}$ & $\begin{array}{l}2.66(0.8) \\
\text { range = } 1- \\
5\end{array}$ & $U=905984.0, p<.001, E_{t a}^{2}=0.03 *$ \\
\hline \multicolumn{4}{|c|}{ Table 3 Health ratings for high and low caffeine consumers. * denotes significant difference $(p<0.05)$} \\
\hline $\begin{array}{l}\text { A targeted analysis incl } \\
\text { completed. Variables a } \\
\text { group on medical outce } \\
\text { caffeine consumers we } \\
\text { consumers. No other } \mathrm{m}\end{array}$ & $\begin{array}{l}\text { g only participants } \\
\text { resented in Table } 4 \\
\text { with slightly lower } \\
\text { gnificantly more lik } \\
\text { cal condition signifi }\end{array}$ & $\begin{array}{l}\text { t had a Me } \\
\text { erall there } \\
\text { alified rates } \\
\text { to have hi६ }\end{array}$ & $\begin{array}{l}\text { cal Examination Report was } \\
\text { las a significant effect of caffeine } \\
\text { the high caffeine group. The lower } \\
\text { blood pressure than the high caffeine } \\
\text { affeine groups. }\end{array}$ \\
\hline
\end{tabular}

\begin{tabular}{|c|c|c|c|}
\hline $\begin{array}{l}\text { Variable } \\
\text { (n low caffeine: } \mathrm{n} \text { high } \\
\text { caffeine) }\end{array}$ & $\begin{array}{l}\text { Low caffeine } \\
\text { consumers } \\
\text { Percentage or } \\
\text { Mean (SD }\end{array}$ & $\begin{array}{l}\text { High caffeine } \\
\text { consumers } \\
\text { Percentage or } \\
\text { Mean (SD) }\end{array}$ & \\
\hline $\begin{array}{l}\text { Medical outcome } \\
(993: 815)\end{array}$ & $\begin{array}{l}\text { Qualified: } 60.3 \% \\
\text { Periodic: } 36.5 \% \\
\text { Temp. Disqu.: } 1.5 \% \\
\text { Failed: } 1.7 \%\end{array}$ & $\begin{array}{l}\text { Qualified: } 58.4 \% \\
\text { Periodic: } 36.2 \% \\
\text { Temp. Disqu.: } 2.5 \% \\
\text { Failed: } 1.7 \%\end{array}$ & $\begin{array}{l}\chi^{2}(3)=8.757, p=.033, \phi_{c}= \\
.070^{*}\end{array}$ \\
\hline $\begin{array}{l}\text { Diabetes diagnosis } \\
(1358: 1137)\end{array}$ & $4.9 \%$ & $6.0 \%$ & $\begin{array}{l}\chi^{2}(1)=1.325, p=.250, \phi_{c}= \\
.023\end{array}$ \\
\hline
\end{tabular}




\begin{tabular}{lccl}
$\begin{array}{l}\text { High blood pressure } \\
\text { diagnosis }\end{array}$ & $17.7 \%$ & $14.4 \%$ & $\begin{array}{l}\chi^{2}(1)=5.025, p=.029, \phi_{c}= \\
.045^{*}\end{array}$ \\
$\begin{array}{l}\text { (1358:1137) } \\
\begin{array}{l}\text { OSA diagnosis } \\
\text { (1358:1137) }\end{array}\end{array}$ & $8.6 \%$ & $9.9 \%$ & $\begin{array}{l}\chi^{2}(1)=1.294, p=.255, \phi_{c}= \\
.023\end{array}$ \\
$\begin{array}{l}\text { Cardio vascular } \\
\text { disease diagnosis }\end{array}$ & $0.9 \%$ & $1.2 \%$ & $\begin{array}{l}\chi^{2}(1)=2.549, p=.110, \phi_{c}= \\
\text { (211:187) }\end{array}$ \\
\hline
\end{tabular}

Table 4 Health outcomes from the Medical Examination Report *denotes significant difference $(p<$ $0.05)$

\section{Binary logistic regression}

Table 5 outlines the odds ratios, 95\% confidence intervals $(\mathrm{Cl})$ and significance levels for each variable in the model. The model considers data from 2,841 participants with full eligible datasets (94.5\%). With all variables included in the logistic regression, the model was statistically significant $\chi^{2}(22)=647.43, p<0.001$ (NagelkerkeR ${ }^{2}=0.27$ ). Compared to the lower caffeine group, five variables had greater odds of being associated with the higher caffeine group. The odds of being in the high caffeine group increased with increasing number of months having held a CDL,. For safety indicators, the odds of being in the high caffeine group increased with increasing scores on the DDDI for both negative emotions and aggressive driving. For health factors, the odds of being in the high caffeine group increased with greater ESS and reporting use of tobacco products.

Compared to the low caffeine group five variables have lower odds of being associated with the high caffeine group. For safety indicators, the odds of being in the high caffeine group decreased with increasing score on the DDDI risky driving score. For health variables, the odds of being in the high caffeine group decreased with: increased average hours sleep, having a consistent regular sleep schedule, participation in 2, 3, 4, 5, 6 or 8 exercise sessions per week (compared to 0 ) and increased rating of diet. In each case, the healthier the behaviour (e.g. more hours' sleep, having a regular sleep schedule and participating in exercise) decreased the odds of a driver being associated with the high caffeine group.

The following variables were not significant predictors in the model: self-reported crashes in the previous three years, EDS, OSA risk or regularity of sleep schedule.

\begin{tabular}{lllll}
\hline & & Odds Ratio & $95 \% \mathrm{Cl}$ & $\mathrm{p}$ \\
\hline Months held a CDL & & 1.01 & $1.01-1.01$ & $<.001^{*}$ \\
Self-report crash in previous & No & 1.00 & Referent & .065 \\
three years & Yes & 1.20 & $0.99-1.45$ & \\
DDDI Negative emotions & No & 1.00 & Referent & $<.001^{*}$ \\
& Yes & 1.08 & $1.05-1.10$ & \\
DDDI aggressive driving & No & 1.00 & Referent & $.001^{*}$ \\
& Yes & 1.07 & $1.03-1.11$ & \\
DDDI risky driving & No & 1.00 & Referent & $<.001^{*}$ \\
& Yes & 0.93 & $0.91-0.96$ & \\
ESS score & & 1.05 & $1.02-1.08$ & $.005^{*}$ \\
EDS (ESS $\geq 12)$ & No & 1.00 & Referent & .261 \\
& Yes & 1.27 & $0.84-1.93$ & \\
High risk of OSA (BQ) & No & 1.00 & Referent & .442 \\
& Yes & 1.11 & $0.85-1.46$ & \\
Average hours sleep per night & & 0.93 & $0.88-0.98$ & $0.12^{*}$ \\
Regular sleep schedule & No & 1.00 & Referent & \\
\hline
\end{tabular}




\begin{tabular}{lllll}
\hline & Sometimes & 0.81 & $0.63-1.03$ & .089 \\
& Yes & 0.77 & $0.60-0.98$ & $.035^{*}$ \\
Use tobacco products & No & 1.00 & Referent & $<.001^{*}$ \\
& Yes & 3.80 & $3.21-4.53$ & \\
Does exercise & No & 1.00 & Referent & .571 \\
Number of moderate exercise & 0 & 0.87 & $0.53-1.41$ & \\
Sessions per week & 1.00 & Referent & \\
& 2 & 0.66 & $0.34-1.31$ & .235 \\
& 3 & 0.27 & $0.15-0.49$ & $<.001^{*}$ \\
& 4 & 0.34 & $0.20-0.59$ & $<.001^{*}$ \\
& 5 & 0.38 & $0.22-0.64$ & $<.001^{*}$ \\
& 6 & 0.37 & $0.21-0.65$ & $.001^{*}$ \\
Self-rating of diet & 7 & 0.35 & $0.19-0.64$ & $.001^{*}$ \\
& 8 & 0.53 & $0.23-1.18$ & .122 \\
\hline
\end{tabular}

Table 5 Logistic regression odds ratios, Cls and significance level for each variable compared between low and high caffeine use groups.

\section{DISCUSSION}

This paper considers associations between truck drivers' high caffeine consumption, driving safety and health. 1,354 high ( $\geq 5$ drinks per day) caffeine consumers were compared to 1,653 low (1 drink per day) caffeine consumers. Participants completed a self-report questionnaire including several standardised survey tools, as well as undertaking a medical examiner report and three years of follow up of crash and violation data. Results demonstrate that high caffeine consumption is associated with poor sleep (shorter average sleep time and higher ESS), negative health behaviours (smoking, poor diet and infrequent exercise) and poorer driving safety indicators (self-reported crashes, negative emotions and aggressive driving).

High caffeine consumption was defined as $\geq 5$ drinks per day as this represents intake at the $90^{\text {th }}$ percentile based on average American consumption (Mitchell et al., 2014). This criterion resulted in $12.5 \%$ of the original 10,868 total available participant pool beginning classified as high caffeine consumers, demonstrating that a greater proportion or truck drivers are high caffeine consumers than might be expected from the average American population. The over representation of high caffeine consumption in truck drivers provides further justification for the relevance of this and future research focused specifically on high caffeine consuming truck drivers.

Previous research with truck drivers has reported a protective effect of caffeine (Heaton \& Griffin 2015; Sharwood et al., 2013) in terms of reducing crash risk, compared with no caffeine consumption. Therefore, it might have been expected that high caffeine consumers would have fewer crashes and safer driving behaviours than low caffeine consumers. In contrast, the current study found that truck drivers who consumed high levels of caffeine had a greater tendency for selfreporting aggressive driving on the DDDI and were more likely to self-report a crash in the previous three years than low caffeine consumers. A greater proportion of high caffeine consumers had a crash (both MCMIS and carrier reported) during the three year follow up period than low caffeine consumers, however, this was not a statistically significant difference. It is not clear why previous crashes would significantly differ but crashes during the follow up period would not. Possible influences on this difference are because of the dissimilar data collection methods (self-report vs objective crash report) and because the follow up objective crashes considered truck crashes only, 
whereas the self-report also included personal vehicle crashes. In neither case were crashes significantly lower in the high caffeine group, and the lack of benefit from high caffeine consumption in the current study compared to the positive effects in previous work demonstrates a complexity in the relationship between caffeine and safety.

The current work did not support the benefits of caffeine consumption reported in previous studies. When comparing between studies it is important to note the differences in approach to how caffeine consumption was defined. The current work compared caffeine consumers of different levels, rather than grouping all caffeine consumers together. This is a different approach from those of the previous studies reporting benefits of habitual caffeine consumption in truck drivers.

Sharwood et al. (2013) used a binary approach whereby any caffeine consumption was compared to no caffeine. A limitation of this approach is that a bias is introduced whereby it is not possible to separate the potential influence of the caffeine itself from the potential trait or genetic influences which lead an individual to decide to consume caffeine (Roehrs \& Roth, 2008). The current work excludes nil caffeine users. Heaton and Griffin (2015) reported a dose response reduction in safety critical events per increase in caffeinated drinks consumed. This approach provides important understanding of the associations of caffeine and safety for the truck driving population as a whole but does not give detailed insight into the specific case of high caffeine users. The participant pool in Heaton and Griffin (2015) consumed a mean of two caffeinated drinks per day (in line with that of the general US population (Mitchell et al., 2014)), making the profile of caffeine consumption markedly different from the current work. Furthermore, Heaton and Griffin (2015) also noted that the safety benefit was not uniform for all types of SCE. For example, in participants aged 30 to 39 years there was a $26 \%$ increase in collisions or near-collisions with increased daily caffeine consumption. The relationship between caffeine and safety in truck drivers appears to be complex. Focusing on specific groups of interest, for example, unusually high caffeine consumers, will help unpack this issue. Taking an approach which isolates and compares extreme groups affords some clarity of view in the current work, suggesting that for truck drivers who consume unusually high levels of caffeine the potential protective effect of caffeine on safety cannot be assumed.

Furthermore, these previous studies were primarily interested in safety rather than driver health. The current work brings new understanding in the association between negative health behaviours (e.g. smoking, poor diet, alcohol consumption) and caffeine consumption. Despite the differences in approach, when considering the current findings and those of previous work together, it could be suggested that it is caffeine consumption at low and moderate doses which is protective rather than caffeine consumption per se.

Compared with low caffeine consumers, high caffeine consumers report having poorer sleep and feeling sleepier during the day. Higher ESS scores and fewer number of hours sleep per night were both associated with increased odds of being in the high caffeine group. Furthermore, EDS is overrepresented in the high caffeine group. This greater tendency for daytime sleepiness and poorer sleep may be because the high caffeine consumption is impairing night time sleep quality and quantity (Carrier et al., 2009). It is probable that higher caffeine consumption and daytime sleepiness have a circular relationship. If drivers feel sleepy during the day they may consume caffeine to increase alertness. However, due to the long half-life of caffeine (Kaplan et al., 1997) it may impair their night time sleep quality resulting in insufficient sleep and continued sleepiness the following day. Within the subset of high caffeine consumers approximately $20 \%$ consumed more than 10 caffeinated drinks per day. This group were not specifically targeted in the analysis due to the small sample size. However, extreme high levels of caffeine consumption have been shown to result in a dramatic decrease in total sleep time (Sanchez-Ortuno et al., 2005). Future research may wish to consider safety and health implications for extreme caffeine consumption. 
It should be noted that the current work compares between different levels of habitual caffeine consumption. The acute effect of caffeine and implications for caffeine as a countermeasure to driver sleepiness in high caffeine consumers cannot be commented on from the current design. Caffeine is known to improve task performance (e.g., Metz, 2011; Reyner \& Horne 2000; Smith, 2002) and is recommended as a countermeasure to driver sleepiness (UK Government 2018). The acute benefits of caffeine on reaction time are observed even in habitual caffeine users (Haskell et al., 2005), suggesting that caffeine is probably an effective countermeasure to driver sleepiness in habitual caffeine consumers. However, research evidence is needed to support the efficacy of caffeine as a countermeasure to driver sleepiness particularly for truck drivers who are unusually high caffeine consumers.

The high caffeine consumers had held their CDL for significantly longer and were significantly older than low caffeine consumers. These were small practical differences and high consumers were on average only one year older, although they had held their CDL for an average of two years longer. It appears that the longer a person works in the industry, the more likely they are to consume a high amount of caffeine. The high caffeine group being slightly older contrasts to the findings of Heaton and Griffin (2015), who report increasing age to be associated with decreased caffeine consumption. Future research may wish to consider a longitudinal method, to confirm whether caffeine consumption increases or decreases with years holding a CDL and if this is independent of age.

The current work considers driver health in addition to safety indicators. Consistently, high caffeine consumers demonstrated poor health behaviours for all relevant variables collected (alcohol, diet and exercise). The greatest association was with use of tobacco products, where the odds of being in the high caffeine group was 3.8 times greater than being in the low caffeine group. Fewer of the high caffeine consumers exercised compared to the low caffeine consumers, but the odds of being in the high caffeine group depended on how many exercise sessions per week drivers undertook. Having one moderate exercise session per week did not differ between caffeine consumption groups, however, two moderate exercise sessions per week reduced the odds of being in the high caffeine group. The high caffeine consuming truck drivers also drank significantly more alcohol per week. Previous research considering both alcohol and caffeine consumption has focused on college students. In college students high caffeine consumption in the form of energy drinks is strongly associated with self-report smoking, alcohol intake, poor diet, low exercise and alcohol dependency (Attila et al., 2011).

In light of the differences in health-related behaviours between the two groups it was unexpected that $\mathrm{BMI}$ and the prevalence of the majority of medical conditions did not differ between groups. $\mathrm{A}$ larger proportion of high caffeine consumers were at high risk of OSA from the BQ but this was not reflected in medical diagnosis. This difference may be because of underdiagnosis of OSA in this population. As untreated OSA is a disqualifying condition for truck drivers, many are reluctant to undergo screening/testing (Mabry et al., 2012). More than half of the participating drivers were obese. This universal high level of obesity is concerning regardless of caffeine consumption and should be considered as a target for any workplace health intervention. These associations between negative health behaviour and caffeine consumption suggest that any fatigue risk management programme for truck drivers should not focus on sleep/fatigue as an isolated component of health. Rather, it would be beneficial to address health in an integrated and holistic manner with strategies to improve health also including improving sleep and reducing caffeine intake. There is a need to improve the health of truck drivers because as a group they are prone to poor health (Apostolopoulos et al., 2013; Mabry et al., 2016).

In designing any intervention with an aim to reduce caffeine consumptions the results of the current study suggest two key areas of content to be particularly important. First, with regard to sleep 
health, an intervention should target increasing sleep duration and maintaining a regular sleep schedule, as these variables were both significant predictors of a driver being a high caffeine consumer. Practical advice on the importance of sleep and sleep hygiene within an intervention have the potential to be effective, however, care must be taken in how these are implemented as although research evidence is generally supportive of sleep hygiene training the direct effects of any particular recommendation and relevance for truck drivers as a specific population remains under researched (Irish et al., 2015). Second, an intervention should include strategies to stop using tobacco, increase the number of moderate exercise sessions to at least two per week, and improve diet. Each of these factors was a significant predictor of being in the high caffeine group. In general, when interventions targeted at improving health have been tested with truck drivers there is evidence that health behaviours can be improved ( $\mathrm{Ng}$ et al., 2015). However, workplace barriers such as lack of access to healthy food would also need to be addressed to maximise the benefit of any driver targeted intervention (Apostolopoulos et al., 2011). Another consideration is how long a driver has held their CDL. The more experienced the driver the greater are the odds that they will be a high caffeine user. This suggests that interventions may benefit from being tailored depending on driving experience, for example, interventions with new drivers may consider focusing on maintaining good sleep and health behaviours, whereas for interventions with experienced drivers it may be more applicable to focus on changing health behaviour. In implementing any intervention, using an integrated approach within an occupational setting has been shown to have the greatest likelihood to improve health outcomes (Chapman \& Naweed, 2015; Mabry et al., 2013).

Low caffeine consumers were slightly more likely to receive a Qualified status by medical examiner report and high caffeine consumers more likely to receive a Temporary Disqualified. However, there is potential that the accuracy of information within the Medical Examiner Report form is variable. The reports were all completed by a certified medical examiner, but the qualification of the individual practitioner varied between participants, for example, a medical doctor and a chiropractor would be considered equally qualified to complete the Medical Examiner Report. It is possible that diagnosis rates may differ depending on examiner qualification, for example, a medical doctor may be better able to identify underlying medical disorders than a chiropractor. Future research should consider the impact of practitioner qualification on Medical Examiner Reports.

The limitations of the work should be noted. The survey data may be considered to reflect a crosssectional convenience sample, and as such, results may be biased in an unknown way. The information collected from the background questionnaire was self-reported. As with all self-report data, accuracy relies on honesty and accurate recollection. All surveys were completed independently from the employer and participants were made aware that the individual findings would not be reported to their employer. It is expected that this would increase participants' honesty in responding, particularly to sensitive information such as number of previous crashes. A change in employer requirements for Medical Examiner Reports during the data collection period resulted in missing data from some participants. Caffeine consumption was recorded by self-report. The granularity and robustness of the data is therefore not significant enough for answering broad research questions, such as questions related to in-depth profiling of different types of caffeine consumers, comparison between types of caffeine drink e.g. energy drinks and coffee, variability of caffeine intake on work vs non-work days, nor is it possible to predict any change in behaviours at the level of individual number of drinks consumed. Furthermore, the analysis here identifies associations rather than effects of caffeine, so it cannot be used to draw conclusions as to whether high caffeine consumption causes any of the reported behaviours. Future research may wish to consider these aspects in more depth, for example, by collecting more objective data through daily monitoring of caffeine intake. 
It is a strength of the work that the data was collected in an applied environment documenting realworld work practices. However, there are difficulties in studying the real-world impact of caffeine outside of controlled experiments. One reason is because the caffeine content of brewed drinks is not standard. The volume of caffeine in coffee varies from cup to cup and is influenced by brewing process and the individual beans themselves (Roehrs \& Roth, 2008). Within controlled laboratory experiments measured doses of caffeine can be administered, however, in applied research this is not possible as the average individual will have no way or knowing exactly how much caffeine they are consuming in a particular brewed drink. As such any analysis based on number of caffeinated drinks is an estimate of caffeine consumption. Furthermore, the impact of caffeine is known to vary according to body weight. Without knowing the exact mg of caffeine consumed it was not possible to consider caffeine consumption in relation to $\mathrm{kg}$ of body weight. It is worth noting that the impact of $\mathrm{mg}$ of caffeine per $\mathrm{kg}$ was likely to be similar for both groups as, overall, there was no significant difference in weight between the high and low caffeine consumer groups.

\section{Conclusion}

Shorter sleep duration, irregular sleep schedules and higher daytime sleepiness (ESS) are apparent in high ( $\geq 5$ drinks) compared with low ( 1 drink) caffeine consumers in a truck driving population. High caffeine consumption was also associated with poor health behaviours, including tobacco use, frequency of alcohol consumption, less exercise and poorer diet. Safety indicators of DDDI score and self-reported crashes in the previous three years are greater in high caffeine consumers. Work place interventions for truck drivers aimed at improving driving safety should take a holistic approach to improving driver sleep and health together, recognising the association of high caffeine use with poor sleep, health and driving safety.

\section{ACKNOWLEDGMENTS}

The Federal Motor Carrier Safety Administration funded part of this research (Contract DTMC75-10$\mathrm{H}$-00007). The opinions expressed in this manuscript are those of the authors and do not reflect the opinions of any U.S. government agency. Dr Filtness was funded by an internal Loughborough University grant from the Transport Technologies Beacon to attend VTTI and undertake this work.

\section{REFERENCES}

American Trucking Associations. (2018). American trucking trends 2018. Arlington, VA: American Trucking Association. Retrieved from https://www.trucking.org/article/New-Report-Finds-TruckingIndustry-Revenues-Topped-\$700-Billion

Apostolopoulos, Y., Sönmez, S., Shattell, M., Haldeman, L., Strack, R., \& Jones, V. (2011). Barriers to truck drivers' healthy eating: Environmental influences and health promotion strategies. Journal of Workplace Behavioral Health, 26(2), 122-143.

Apostolopoulos, Y., Sönmez, S., Shattell, M. M., Gonzales, C., \& Fehrenbacher, C. (2013). Health survey of US long-haul truck drivers: work environment, physical health, and healthcare access. Work, 46(1), 113-123.

Attila, S., \& Çakir, B. (2011). Energy-drink consumption in college students and associated factors. Nutrition, 27(3), 316-322. 
Bioulac, S., Franchi, J. A. M., Arnaud, M., Sagaspe, P., Moore, N., Salvo, F., \& Philip, P. (2017). Risk of motor vehicle accidents related to sleepiness at the wheel: a systematic review and metaanalysis. Sleep, 40(10).

Burks, S.V., Anderson, J.E., Bombyk, M., Haider, R., Ganzhorn, D., Jiao, X., Lewis, C., Lexvold, A., Liu, H., Ning, J., Toll, A., Hickman, J.S., Mabry, J.E., Berger, M., Malhotra, A., Czeisler, C.A., \& Kales S.N. (2016). Nonadherence with employer-mandated sleep apnea treatment and increased risk of serious truck crashes. Sleep, 39(5): 967-75.

Camden, M. C., Hickman, J. S., Soccolich, S. A., \& Hanowski, R. J. (2014). Prescription and Over-theCounter Drug Use and its Relationship to Involvement in Safety-Critical Events.

Carrier J, Paquet J, Fernandez-Bolanos M, Girouard L, Roy J, Selmaoui B, et al. Effects of caffeine on daytime recovery sleep: a double challenge to the sleep-wake cycle in aging. Sleep Med 2009;10:1016-24.

Chapman, J., \& Naweed, A. (2015). Health initiatives to target obesity in surface transport industries: Review and implications for action. Evidence Base, 2015(2), 1-20.

Corti R, Binggeli C, Sudano I, Spieker L, Hanseler E, Ruschitzka F, et al. Coffee acutely increases sympathetic nerve activity and blood pressure independently of caffeine content. Circulation 2002;106:2935-40.

Dula, C.S., \& Ballard, M.E. (2003). Development and evaluation of a measure of dangerous, aggressive, negative emotional, and risky driving. Journal of Applied Social Psychology, 33(2): 263282

FMCSA (n.d.) Medical examination report for commercial driver fitness determination. Retreieved from:

https://www.fmcsa.dot.gov/sites/fmcsa.dot.gov/files/docs/Medical_Examination_Report_for_Com mercial_Driver_Fitness_Determination_649-F\%286045\%29.pdf

Fredholm B, Battig K, Holmen J, Nehlig A, Zvartau E. (1999) Actions of caffeine in the brain with special reference to factors that contribute to its widespread use. Pharmacol Rev 51:83-133.

Giles, G. E., Mahoney, C. R., Brunyé, T. T., \& Kanarek, R. B. (2017). Cautiously Caffeinated: Does Caffeine Modulate Inhibitory, Impulsive, or Risky Behavior?. Journal of Caffeine Research, 7(1), 7-17.

Gonçalves, L. D. S., Painelli, V. D. S., Yamaguchi, G., Oliveira, L. F. D., Saunders, B., da Silva, R. P., ... \& Gualano, B. (2017). Dispelling the myth that habitual caffeine consumption influences the performance response to acute caffeine supplementation. Journal of Applied Physiology, 123(1), 213-220.

Hardinge, M. 2008, "Obstructive sleep apnoea", Medicine, vol. 36, no. 5, pp. 237-241.

Haskell, C. F., Kennedy, D. O., Wesnes, K. A., \& Scholey, A. B. (2005). Cognitive and mood improvements of caffeine in habitual consumers and habitual non-consumers of caffeine. Psychopharmacology, 179(4), 813-825.

Heatherley, S. V. (2011). Caffeine withdrawal, sleepiness, and driving performance: What does the research really tell us?. Nutritional neuroscience, 14(3), 89-95.

Heaton, K., \& Griffin, R. (2015). The effects of caffeine use on driving safety among truck drivers who are habitual caffeine users. Workplace health \& safety, 63(8), 333-341.

Howard, M. E., Desai, A. V., Grunstein, R. R., Hukins, C., Armstrong, J. G., Joffe, D., et al. (2004). Sleepiness, sleep-disordered breathing, and accident risk factors in commercial vehicle drivers. 
American Journal of Respiratory and Critical Care Medicine, 170(9): 1014-1021. doi: $10.1164 / \mathrm{rccm} .200312-17820 \mathrm{C}$

Irish, L. A., Kline, C. E., Gunn, H. E., Buysse, D. J., \& Hall, M. H. (2015). The role of sleep hygiene in promoting public health: A review of empirical evidence. Sleep medicine reviews, 22, 23-36.

Johns MW (1991) A new method for measuring daytime sleepiness: the Epworth sleepiness scale. Sleep 14: 540-545.

Jonah, B.A. (1997). Sensation seeking and risky driving: a review and synthesis of the literature. Accident Analysis and Prevention, 29(5): 651-665

Jones, H. A., \& Lejuez, C. W. (2005). Personality correlates of caffeine dependence: the role of sensation seeking, impulsivity, and risk taking. Experimental and clinical psychopharmacology, 13(3), 259.

Kaplan GB, Greenblatt DJ, Ehrenberg BL, Goddard JE, Cotreau MN, Harmatz JS, et al. (1997) Dosedependent pharmacokinetics and psychomotor effect of caffeine in humans. J Clin Psychopharm 37:693-703

Mabry, J.E. (2019). Findings from the Commercial Driver Safety Risk Factors Study. Presented at the 98th Transportation Research Board in Washington, D.C.

Mabry, J.E., Hosig, K., Hanowski, R., Zedalis, D., Gregg, J., Herbert, W.G. (2016) Prevalence of Metabolic Syndrome in Commercial Truck Drivers: A Review. Journal of Transport and Health 3(3):413-421.

Mabry, J.E. Hickman, J.S., \& Hanowski, R.J. (2013). Case Study on Worksite Health and Wellness Program for Commercial Motor Vehicle Drivers. Blacksburg, VA: The National Surface Transportation Safety Center for Excellence.

Mabry, J.E. Hickman, J.S., \& Hanowski, R.J. (2012). Case Study on the Impact of Treating Sleep Apnea in Commercial Motor Vehicle Drivers. Report 12-UF-017. Blacksburg, VA: The National Surface Transportation Safety Center for Excellence.

Magkos F, Kavouras S. (2005) Caffeine use in sports, pharmacokinetics in man, and cellular mechanisms of action. Crit Rev Food Sci Nutr 45:535-62

McCartt, A. T., Rohrbaugh, J. W., Hammer, M. C., \& Fuller, S. Z. (2000). Factors associated with falling asleep at the wheel among long-distance truck drivers. Accident Analysis \& Prevention, 32(4), 493504.

Mets, M. A., Ketzer, S., Blom, C., Van Gerven, M. H., Van Willigenburg, G. M., Olivier, B., \& Verster, J. C. (2011). Positive effects of Red Bull ${ }^{\circledR}$ Energy Drink on driving performance during prolonged driving. Psychopharmacology, 214(3), 737-745.

Mitchell, D. C., Knight, C. A., Hockenberry, J., Teplansky, R., \& Hartman, T. J. (2014). Beverage caffeine intakes in the US. Food and Chemical Toxicology, 63, 136-142.

Netzer, N., Stoohs, R., Netzer, C., Clark, K., \& Strohl, K. (1999). Using the berlin questionnaire to identify patients at risk for the sleep apnea syndrome. Annals of Internal Medicine, 131(7): 485-491.

$\mathrm{Ng}$, M. K., Yousuf, B., Bigelow, P. L., \& Van Eerd, D. (2015). Effectiveness of health promotion programmes for truck drivers: A systematic review. Health Education Journal, 74(3), 270-286

Reyner, L. A., \& Horne, J. A. (2000). Early morning driver sleepiness: effectiveness of $200 \mathrm{mg}$ caffeine. Psychophysiology, 37(2), 251-256. 
Roehrs, T., \& Roth, T. (2008). Caffeine: sleep and daytime sleepiness. Sleep medicine reviews, 12(2), 153-162.

Sanchez-Ortuno M, Moore N, Taillard J, Valtat C, Leger D, Bioulac B, et al. (2005) Sleep duration and caffeine consumption in a French middle-aged working population. Sleep Med 6:247-

Sharwood, L. N., Elkington, J., Meuleners, L., Ivers, R., Boufous, S., \& Stevenson, M. (2013). Use of caffeinated substances and risk of crashes in long distance drivers of commercial vehicles: casecontrol study. BMJ, 346, f1140

Smith, A. (2002). Effects of caffeine on human behavior. Food and chemical toxicology, 40(9), 12431255.

Thiese, M. S., Ott, U., Robbins, R., Effiong, A., Murtaugh, M., Lemke, M. R., ... \& Hartenbaum, N. (2015). Factors associated with truck crashes in a large cross section of commercial motor vehicle drivers. Journal of occupational and environmental medicine, 57(10), 1098-1106.

Tregear, S., Reston, J., Schoelles, K., \& Phillips, B. (2009). Obstructive sleep apnea and risk of motor vehicle crash: systematic review and meta-analysis. Journal of clinical sleep medicine, 5(06), 573581.

UK Government (2018) Rule 91 https://www.gov.uk/guidance/the-highway-code/rules-for-drivers-andmotorcyclists-89-to-102

Walker, M. (2017). Why we sleep: The new science of sleep and dreams. Penguin UK. 